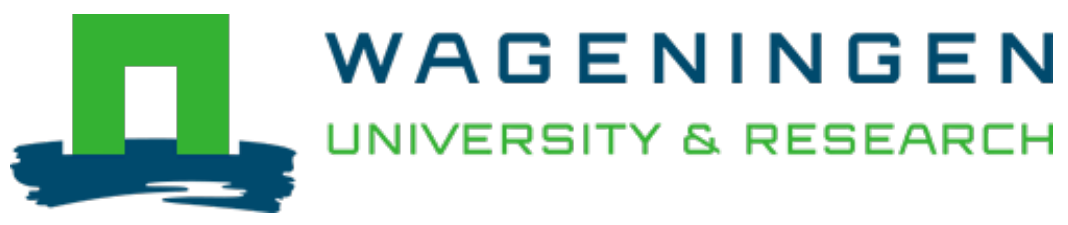

\title{
Uncommonly high levels of 3-deoxyanthocyanidins and antioxidant capacity in the leaf sheaths of dye sorghum
}

Journal of Agricultural and Food Chemistry

Kayode, A.P.P.; Nout, M.J.R.; Linnemann, A.R.; Hounhouigan, J.D.; Berghofer, E. et al https://doi.org/10.1021/jf103963t

This publication is made publicly available in the institutional repository of Wageningen University and Research, under the terms of article $25 \mathrm{fa}$ of the Dutch Copyright Act, also known as the Amendment Taverne. This has been done with explicit consent by the author.

Article 25 fa states that the author of a short scientific work funded either wholly or partially by Dutch public funds is entitled to make that work publicly available for no consideration following a reasonable period of time after the work was first published, provided that clear reference is made to the source of the first publication of the work.

This publication is distributed under The Association of Universities in the Netherlands (VSNU) 'Article $25 \mathrm{fa}$ implementation' project. In this project research outputs of researchers employed by Dutch Universities that comply with the legal requirements of Article $25 \mathrm{fa}$ of the Dutch Copyright Act are distributed online and free of cost or other barriers in institutional repositories. Research outputs are distributed six months after their first online publication in the original published version and with proper attribution to the source of the original publication.

You are permitted to download and use the publication for personal purposes. All rights remain with the author(s) and / or copyright owner(s) of this work. Any use of the publication or parts of it other than authorised under article $25 \mathrm{fa}$ of the Dutch Copyright act is prohibited. Wageningen University \& Research and the author(s) of this publication shall not be held responsible or liable for any damages resulting from your (re)use of this publication.

For questions regarding the public availability of this publication please contact openscience.library@wur.nl 


\title{
Uncommonly High Levels of 3-Deoxyanthocyanidins and Antioxidant Capacity in the Leaf Sheaths of Dye Sorghum
}

\author{
A. P. Polycarpe Kayodé, ${ }^{*,+}$ M. J. Rob Nout, ${ }^{\ddagger}$ Anita R. Linnemann, ${ }^{\S}$ Joseph D. Hounhouigan, ${ }^{\dagger}$ \\ Emmerich Berghofer," and Susanne Siebenhandl-Ehn" \\ ${ }^{\dagger}$ Département de Nutrition et Sciences Alimentaires, Université d’Abomey-Calavi, 01 BP 526 Cotonou, Benin

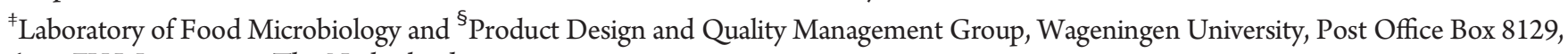 \\ 6700 EV Wageningen, The Netherlands \\ "Department of Food Science and Technology, University of Natural Resources and Life Sciences, Muthgasse 18, 1190 Vienna, Austria
}

\begin{abstract}
Extracts from leaf sheaths of farmers' varieties of dye sorghum cultivated and used in Benin as a source of biocolorings were analyzed for their anthocyanidin and phenolic contents, as well as their antioxidant capacity. The aim was to identify and quantify the types of anthocyanin and phenolic acids. The total anthocyanin content of the leaf sheaths ranged from 13.7 to $35.5 \mathrm{mg}$ of cyanidin 3-glucoside equivalent/g of dry matter (DM), with an average of $27.0 \mathrm{mg} / \mathrm{g}$. The total anthocyanin content is 90 times higher than levels usually reported in fruits and vegetables. Anthocyanin consisted essentially of apigeninidin and luteolinidin, two 3-deoxyanthocyanidins with many applications in food, beverage, and pharmaceutical industries. The apigeninidin content of the leaf sheaths was 30 times higher than that in cereal bran and ranged from 14.7 to $45.8 \mathrm{mg} / \mathrm{g}$, with an average of $31.3 \mathrm{mg} / \mathrm{g}$. The amount of luteolinidin ranged from 0.4 to $2.4 \mathrm{mg} / \mathrm{g}$, with a mean of $1.2 \mathrm{mg} / \mathrm{g}$. The total phenolic content expressed as gallic acid equivalent averaged $95.5 \mathrm{mg} / \mathrm{g}$. The free phenolic acids identified were benzoic acid, $p$-coumaric acid, and $o$-coumaric acid at amounts of $801.4,681.6$, and $67.9 \mu \mathrm{g} / \mathrm{g}$, respectively. The leaf sheaths of dye sorghum have an antioxidant capacity [3.8 $-5.6 \mathrm{mmol}$ of Trolox equivalent (TE)/g of DM] much higher than that reported for cereal bran and fruits and vegetables.
\end{abstract}

KEYWORDS: Dye sorghum, apigeninidin, luteolinidin, 3-deoxyanthocyanidins, biocolorant, antioxidant capacity

\section{INTRODUCTION}

The increasing awareness of environmental pollution and toxicity associated with the use of synthetic dyes has led to a revival of interest in plant-derived dyes ${ }^{1}$ and a demand by consumers for safe natural foods. Food industries use coloring agents to produce foods with various organoleptic and therapeutic attributes. Some of these coloring compounds are synthetic, while others are natural, such as cochenille (E-120), beetroot red (E-162), and anthocyanins (E-163). These natural colorants are safe and have attractive bright colors. In addition, certain functional properties, i.e., antioxidant activities and a reduction of chronic diseases, related to natural pigments make them of particular interest to processors and consumers. A challenge to the food industry is to replace synthetic dyes by natural ones. ${ }^{2}$ Considerable research is currently directed toward the identification and characterization of pigments from plant sources, such as vegetables, ${ }^{3}$ fruits, and flowers.

Sorghum spp. are cereal crops, which are important as a food crop in Africa. ${ }^{4}$ However, not all sorghum is mainly used for food; in Benin, some farmers' varieties, referred to as dye sorghum, are primarily grown for their pigments that are concentrated in the leaf sheaths adjacent to the stem of the plant. ${ }^{5}$ Morphologically, dye sorghum [Sorghum bicolor (L.) Moench] resembles grain sorghum; the main difference is the ability to produce red pigments in the leaf sheaths. Dye sorghum is in the field from May to December. Harvesting of the leaf sheaths starts early, viz., 2 months after planting, and is performed weekly until the plant reaches the flowering stage and the production of the leaf sheath stops. As much as 1.5 tons of leaf sheaths can be harvested per hectare under traditional farming conditions. The production of dye sorghum is primarily performed by rural women, who derive a direct benefit from the commercialization of the leaf sheaths. Dye sorghum has been used in Benin and other African countries for centuries. The watery dye extracted from the leaf sheaths is used as biocolorings for foods (e.g., local cheese and porridge), leather, wickerwork, and ornamental calebashes, as lick stones for cattle, and in traditional medicine. The derived food products have a reddish, bright, and attractive color, which is highly appreciated by consumers. In addition, local people use dye sorghum to prepare a red infusion to treat anemia and menstrual disorders.

Sorghum is known to synthesize a unique class of flavonoid phytoalexins, 3-deoxyanthocyanidins, during defense responses. ${ }^{6,7}$ However, whether the concentration of pigments in the leaf sheaths of dye sorghum is also a defense response has not yet been established. Sorghum is the only plant known to contain significant quantities of luteolinidin and apigeninidin (both 3-deoxyanthocyanidins), which are not commonly found in higher plants. Commonly, anthocyanins are isolated from either the grain or its pericarp. Nip and Burns $s^{8,9}$ isolated apigeninidin and luteolinidin from the seeds of red and white sorghum varieties. Kouda-Bonafos et al. ${ }^{10}$ found apigeninidin in the sheaths of Sorghum caudatum, and both 3-deoxyanthocyanidins are also reported as the major anthocyanidins from black sorghum

Received: October 11, 2010

Accepted: December 22, 2010

Revised: December 18, 2010

Published: January 25, 2011 
Table 1. Dimension Characteristics of Leaf Sheaths of Dye Sorghum Analysed

\begin{tabular}{lccccc}
\multicolumn{1}{c}{ sample origin } & weight $(\mathrm{g})^{a}$ & length $(\mathrm{cm})$ & basal width $(\mathrm{cm})$ & middle width $(\mathrm{cm})$ & terminal width $(\mathrm{cm})$ \\
\hline Parakou $(n=7)^{b}$ & $1.60 \pm 0.44$ & $25.66 \pm 2.68$ & $2.02 \pm 0.50$ & $1.48 \pm 0.43$ & $1.08 \pm 0.43$ \\
Ketou $(n=10)$ & $2.63 \pm 0.54$ & $26.69 \pm 4.37$ & $2.02 \pm 0.56$ & $1.40 \pm 0.46$ & $1.17 \pm 0.31$ \\
Toucountouna $(n=5)$ & $0.76 \pm 0.55$ & $22.28 \pm 2.72$ & $1.88 \pm 0.82$ & $1.38 \pm 0.48$ & $0.94 \pm 0.27$ \\
Boukoumbe $(n=5)$ & $0.90 \pm 0.42$ & $22.18 \pm 3.32$ & $1.96 \pm 0.71$ & $1.20 \pm 0.24$ & $0.80 \pm 0.14$ \\
Paouingnan $(n=9)$ & $2.54 \pm 1.19$ & $26.74 \pm 3.56$ & $1.70 \pm 0.55$ & $1.32 \pm 0.63$ & $1.03 \pm 0.49$ \\
Dassa $(n=6)$ & $2.05 \pm 1.23$ & $27.00 \pm 2.19$ & $1.63 \pm 0.41$ & $1.23 \pm 0.27$ & $0.90 \pm 0.34$ \\
mean & 1.75 & 25.09 & 8.97 & 7.98 & 0.99 \\
$\mathrm{CV}^{c}$ & 45.9 & 9.02 & 8.95 & & 13.5 \\
${ }^{a}$ Mean \pm standard deviation. ${ }^{b} n=$ number of leaf sheath measured. ${ }^{c} \mathrm{CV}=$ coefficient of variation. \\
\hline
\end{tabular}

Table 2. Total Anthocyanin and 3-Deoxyanthocyanidin Contents of Leaf Sheaths of Dye Sorghum ${ }^{a}$

\begin{tabular}{|c|c|c|c|c|}
\hline \multirow[b]{2}{*}{ sample origin } & \multirow{2}{*}{$\begin{array}{c}\text { spectrophotometry } \\
\mathrm{ACY}(\mathrm{mg} \text { of C-3-glc/g) }\end{array}$} & \multicolumn{3}{|c|}{ HPLC } \\
\hline & & apigeninidin $(\mathrm{mg} / \mathrm{g})$ & luteolinidin $(\mathrm{mg} / \mathrm{g})$ & malvidin $(\mathrm{mg} / \mathrm{g})$ \\
\hline Parakou & $26.05 \pm 0.35 c$ & $28.83 \pm 1.79 b$ & $1.07 \pm 0.10 \mathrm{c}$ & $0.79 \pm 0.06 \mathrm{c}$ \\
\hline Ketou & $35.51 \pm 0.14 \mathrm{e}$ & $40.30 \pm 0.87 c$ & $2.35 \pm 0.06 \mathrm{f}$ & $1.03 \pm 0.04 \mathrm{~d}$ \\
\hline Toucountouna & $13.72 \pm 0.28 \mathrm{a}$ & $16.67 \pm 0.23 \mathrm{a}$ & $0.62 \pm 0.01 b$ & $0.59 \pm 0.01 \mathrm{~b}$ \\
\hline Boukoumbe & $34.33 \pm 0.28 \mathrm{~d}$ & $45.76 \pm 0.93 \mathrm{~d}$ & $1.66 \pm 0.02 \mathrm{e}$ & $0.59 \pm 0.01 \mathrm{~b}$ \\
\hline Paouingnan & $18.57 \pm 0.14 b$ & $14.72 \pm 0.11 \mathrm{a}$ & $0.43 \pm 0.04 \mathrm{a}$ & $0.57 \pm 0.00 \mathrm{a}$ \\
\hline Dassa & $34.18 \pm 0.85 \mathrm{~d}$ & $41.46 \pm 0.58 c$ & $1.24 \pm 0.02 \mathrm{~d}$ & $0.84 \pm 0.03 \mathrm{a}$ \\
\hline mean & 27.06 & 31.29 & 1.23 & 0.70 \\
\hline $\mathrm{CV}^{c}$ & 32.53 & 40.68 & 54.79 & 31.67 \\
\hline
\end{tabular}

${ }^{a}$ Results are based on DM. ${ }^{b}$ Mean \pm standard deviation; means with the same letter are not significantly different according to the LSD at the 0.05 level. ${ }^{c} \mathrm{CV}=$ coefficient of variation.

varieties. $^{11,12}$ The 3-deoxyanthocyanidins offer many applications in food, beverage, and pharmaceutical industries. ${ }^{13}$ They are recognized as health-promoting phytochemicals; e.g., it has been demonstrated that they are more cytotoxic on human cancer cells than the 3-hydroxylated anthocyanidin analogues. At $200 \mu \mathrm{M}$, luteolinidin reduced the viability of HL-60 and HepG2 cells by 90 and $50 \%$, respectively. ${ }^{14}$ Recently Yang et al. ${ }^{15}$ demonstrated that the sorghum 3-deoxyanthocyanidins possess strong phase-II enzyme inducer activity and cancer cell growth inhibition properties. However, information on contents and characteristics of pigments from dye sorghum grown in West Africa is scarce.

In the present study, we assessed the anthocyanin and phenolic contents in extracts from leaf sheaths of dye sorghum and their antioxidant capacity. In addition, the anthocyanidins and phenolic acids were characterized by high-performance liquid chromatography (HPLC).

\section{MATERIALS AND METHODS}

Chemicals and Reagents. 6-Hydroxy-2,5,7,8-tetramethylchroman-2-carboxylic acid (Trolox), 2,2'-azinobis(3-ethylbenzothiazoline6-sulfonic acid)diammonium salt (ABTS), 2,4,6-tripyridyl-s-triazine (TPTZ), 2,2'-diphenyl-1-picrylhydrazyl (DPPH), trifluoroacetic acid, potassium persulfate, sodium hydroxide, Folin-Ciocalteu reagent, and phenolic acid standards (gallic acid, protocatechuic acid, 4-OH-benzoic acid, vanillic acid, caffeic acid, $p$-coumaric acid, $o$-coumaric acid, and trans-ferulic acid) were purchased from Sigma-Aldrich (Vienna, Austria), and anthocyanidin standards (apigeninidin, cyanidin 3-glucoside, cyanidin 3-galactoside, cyanidin, delphinidin, luteolinidin, malvidin, peonidin 3-glucoside, pelargonidin, and peonidin) were purchased from Extrasynthese (Genay, France). Acetonitrile was obtained from VWR (Vienna, Austria). Ethyl acetate and methanol were purchased from
Roth (Graz, Austria). All chemicals and solvents used in the study were of HPLC grade.

Plant Materials. Leaf sheaths of varieties of dye sorghum from farmers were collected from fields in six communities in Benin, i.e., Parakou (latitude, $11^{\circ} 15^{\prime} \mathrm{N}$; longitude, $2^{\circ} 23^{\prime} \mathrm{E}$ ), Ketou (latitude, $7^{\circ} 22^{\prime}$ $\mathrm{N}$; longitude, $2^{\circ} 36^{\prime} \mathrm{E}$ ), Toucountouna (latitude, $10^{\circ} 27^{\prime} \mathrm{N}$; longitude, $\left.1^{\circ} 22^{\prime} \mathrm{E}\right)$, Boukoumbe (latitude, $10^{\circ} 10^{\prime} \mathrm{N}$; longitude, $1^{\circ} 6^{\prime} \mathrm{E}$ ), Paouingnan (latitude, $7^{\circ} 34^{\prime} \mathrm{N}$; longitude, $2^{\circ} 2^{\prime} \mathrm{E}$ ), and Dassa-Zounmè (latitude, $7^{\circ} 55^{\prime} \mathrm{N}$; longitude, $1^{\circ} 58^{\prime} \mathrm{E}$ ). The leaf sheaths were from dye sorghum grown in 2008 under natural conditions, characteristic of the Guinea Savannah climate of West Africa. The annual rainfall in the region varies from 1000 to $1300 \mathrm{~mm}$, and the average yearly temperature is $26.5^{\circ} \mathrm{C} .{ }^{16}$ The soil is a tropical ferruginous type. ${ }^{17}$ After harvesting, the leaf sheaths were dried to a moisture content of 7-9\% $(\mathrm{w} / \mathrm{w})$. The leaf sheaths were ground to powder using an Ultra Centrifugal Mill (Retsch GmbH, Haan, Germany) with a $0.1 \mathrm{~mm}$ sieve and, subsequently, stored at $-20{ }^{\circ} \mathrm{C}$ until analysis.

Preparation of Extracts. Samples were extracted in either metha$\mathrm{nol} / \mathrm{HCl}(85: 15, \mathrm{v} / \mathrm{v})$ for anthocyanin determination or methanol $/ \mathrm{H}_{2} \mathrm{O}$ $(85: 15, \mathrm{v} / \mathrm{v})$ for the determination of total phenolics, phenolic acids, and antioxidant capacity. A total of $30 \mathrm{mg}$ of each sample was extracted at room temperature with $10 \mathrm{~mL}$ of solvent under agitation using a magnetic stirrer for $30 \mathrm{~min}$. The mixtures were centrifuged at $2500 \mathrm{~g}$ for $10 \mathrm{~min}$, and the supernatants were collected. The residues were re-extracted twice under the same conditions, resulting in $30 \mathrm{~mL}$ of crude extract. All extracts were used as they were after centrifugation for various analyses.

Total Anthocyanin Determination (ACY). ACY was calculated as described by Abdel-Aal and $\mathrm{Hucl}^{18}$ using cyanidin 3-glucoside as the standard pigment. The absorbance of the pooled extracts was measured after centrifugation at $525 \mathrm{~nm}$ against a reagent blank. ACY was expressed as milligrams of cyanidin 3-glucoside equivalent per $1 \mathrm{~g}$ of powder based on dry matter (DM). 
Total Phenolic Determination (TPC). Total phenolics were measured following the method by Singleton and Rossi ${ }^{19}$ modified as follows: To $300 \mu \mathrm{L}$ of extract, $4.2 \mathrm{~mL}$ of distilled water, $0.75 \mathrm{~mL}$ of Folin-Ciocalteu reagent (Merck, Germany), and $0.75 \mathrm{~mL}$ of sodium carbonate solution $\left(200 \mathrm{~g} \mathrm{~L}^{-1}\right)$ were added. After incubation for $30 \mathrm{~min}$, the optical density was measured at $760 \mathrm{~nm}$ against a blank. Gallic acid was used as the standard, and the results were expressed as gallic acid equivalent (GAE) per gram of sample DM.

HPLC Determination of Anthocyanidins and Phenolic Acids. The profile of anthocyanidins and corresponding glycosides and phenolic compounds was determined using a HPLC system (Shimadzu, Korneuburg, Austria) consisting of a SPD-M10AVP photodiode array detector, a chromatogram integrator, a LC-10ADVP pump, and an online degasser. Data signals were processed on a personal computer (PC) running the LC solution Multi software (Shimadzu, Korneuburg, Austria). Analytical separation of anthocyanidins and phenolic acids was carried out using a Phenomenex Luna $250 \times 4.6$ $\mathrm{mm}, 5 \mu \mathrm{m}$ (HPLC Services, Breitenfurt, Austria) column.

For anthocyanidins, the solvent was removed from the extracts at $40^{\circ} \mathrm{C}$ using a rotary evaporator and the resulting residues were suspended in $2 \mathrm{~mL}$ of methanol. Dissolved anthocyanidin concentrates were passed through a $0.45 \mu \mathrm{m}$ polytetrafluoroethylene (PTFE) filter, and a $20 \mu \mathrm{L}$ aliquot of the sample solution was injected. Elution for anthocyanidins was executed under gradient conditions with (A) $4.5 \%$ formic acid in water and (B) acetonitrile. The solvent gradient was programmed as follows: $10 \% \mathrm{~B}$ at $0 \mathrm{~min}$, increasing to $12 \%$ within $9 \mathrm{~min}$, to $13 \%$ within the next $7.5 \mathrm{~min}, 25 \%$ within the next $13.5 \mathrm{~min}, 90 \%$ within the next $15 \mathrm{~min}$, holding at $90 \%$ for $5 \mathrm{~min}$, followed by a decrease to $10 \%$ within the next $5 \mathrm{~min}$, before equilibration at $10 \%$. The solvent flow rate was set at $0.8 \mathrm{~mL} / \mathrm{min}$, and the chromatogram was recorded at $520 \mathrm{~nm}$ (anthocyanidins and glycosides) and 480 $\mathrm{nm}$ (deoxyanthocyanidins) at $35^{\circ} \mathrm{C}$. Peak areas were used for all calculations. Identification of compounds was performed by comparing the retention time and the ultraviolet (UV) spectra to those of pure substances. Diode array detector (DAD) response was linear for all anthocyanidins and anthocyanins within the calibration range of $0.05-40.0 \mu \mathrm{g} / \mathrm{mL}$, with correlation coefficients exceeding 0.999 . Coefficients of variation for sample replicates were consistently below $10 \%$.

Phenolic acids were quantified as described by Siebenhandl et al. ${ }^{20} \mathrm{~A}$ total of $20 \mu \mathrm{L}$ of sample was injected into the column and eluted under gradient conditions performed with (A) $0.05 \%$ trifluoroacetic acid in water and (B) $0.05 \%$ trifluoroacetic acid in acetonitrile. The solvent gradient was programmed as follows: at $0 \mathrm{~min}, 10 \% \mathrm{~B}$; increasing from 3 to $15 \mathrm{~min}, 15 \% \mathrm{~B}$; $25 \mathrm{~min}, 20 \% \mathrm{~B}$; $30 \mathrm{~min}, 40 \% \mathrm{~B}$; $36-40 \mathrm{~min}, 80 \% \mathrm{~B}$; decreasing thereafter within the next $4 \mathrm{~min}, 10 \% \mathrm{~B}$; and equilibrated before the next injection. The flow rate was $1.0 \mathrm{~mL} / \mathrm{min}$. Analyte detection was at $260 \mathrm{~nm}$ for 4-OH-benzoic and vanillic acids, at 270 $\mathrm{nm}$ for gallic and $o$-coumaric acids, and at $280 \mathrm{~nm}$ for caffeic, $p$-coumaric, and trans-ferulic acids. DAD response was linear for all phenolic acids within the calibration range of $0.06-125.0 \mu \mathrm{g} / \mathrm{mL}$, with correlation coefficients exceeding 0.999. Phenolic acids in the samples were identified by comparing their relative retention times and UV spectra to authentic compounds. Coefficients of variation for sample replicates were consistently below $10 \%$.

Determination of Antioxidant Capacity. Extracts obtained with aqueous methanol were analyzed for their total antioxidant capacity by the ABTS radical cation scavenging assay [Trolox equivalent antioxidant capacity (TEAC)] and the ferric reducing antioxidant power (FRAP) assay. Moreover, the 2,2'-diphenyl-1-picrylhydrazyl (DPPH) radical-scavenging ability of sample extracts was evaluated.

The TEAC assay was analyzed following a modified method by Pellegrini et al. ${ }^{21}$ and Moore et al. ${ }^{22}$ A stable stock solution of ABTS radical cation was produced by reacting a $7 \mathrm{mmol} / \mathrm{L}$ aqueous solution of ABTS with $2.45 \mathrm{mmol} / \mathrm{L}$ potassium persulfate (final concentration) and allowing the mixture to stand in the dark at room temperature for $12-16$
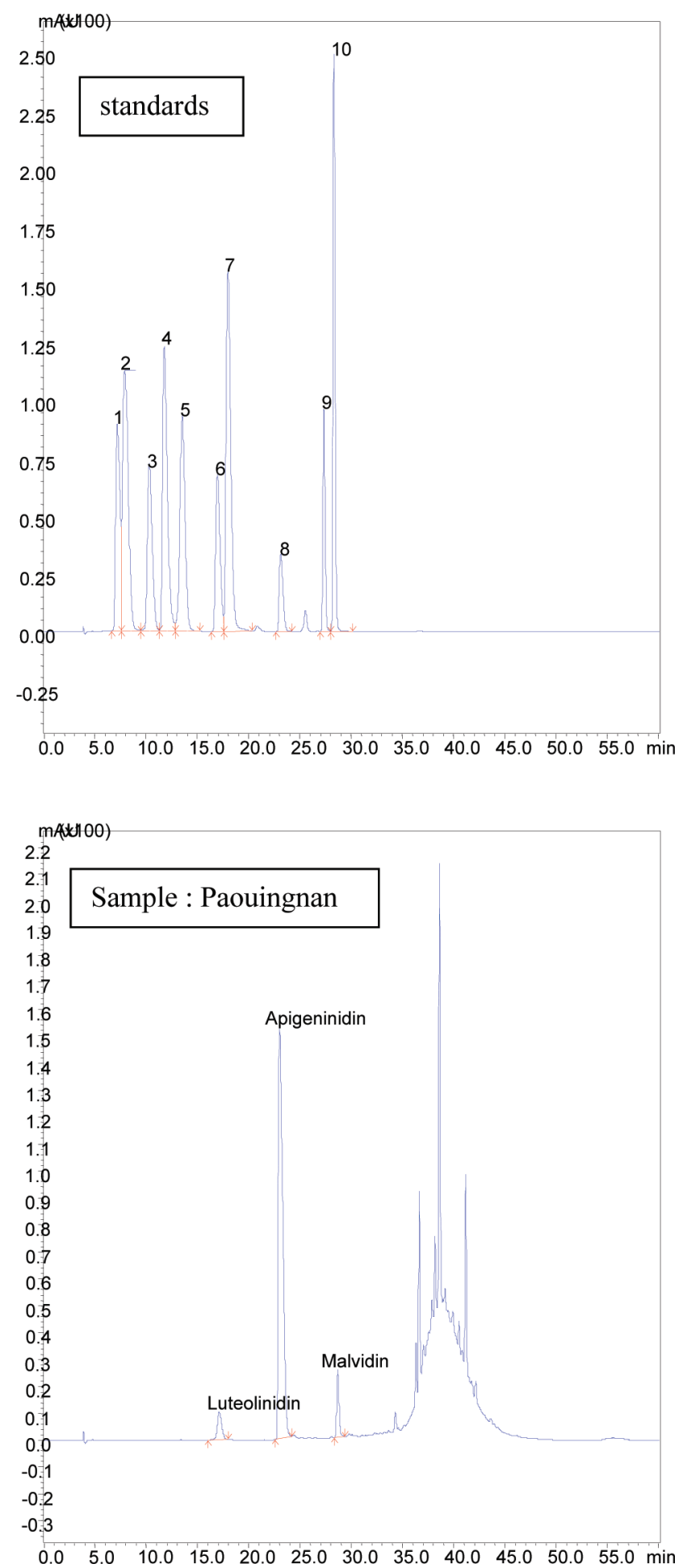

Figure 1. HPLC profiles of anthocyanidins in extract from leaf sheaths of dye sorghum: (1) cyanidin-galactoside, (2) cyanidin-glucoside, (3) pelargonidin-glucoside, (4) delphinidin, (5) peonidin-glucoside, (6) luteolinidin, (7) malvidin-glucoside, (8) apigeninidin, (9) cyanidin, and (10) malvidin.

$\mathrm{h}$ before use. On the day of analysis, an ABTS radical cation working solution was obtained by diluting the stock solution in ethanol to an absorbance of $0.70 \pm 0.02 \mathrm{AU}$ (Absorbance Unit) at $734 \mathrm{~nm}$. A total of $100 \mu \mathrm{L}$ of extract was mixed with $1.25 \mathrm{~mL}$ of the ABTS working solution, and absorbance was read at $734 \mathrm{~nm}$ after a 1 min reaction time. Results were expressed as TEAC in millimoles of Trolox per gram based on DM. 
Table 3. Total Phenolic and Phenolic Acid Contents of Leaf Sheaths of Dye Sorghum ${ }^{a}$

\begin{tabular}{|c|c|c|c|c|}
\hline \multirow[b]{2}{*}{ sample origin } & \multirow{2}{*}{$\begin{array}{c}\text { spectrophotometry } \\
\text { TPC (mg of GAE/g) })^{b}\end{array}$} & \multicolumn{3}{|c|}{ HPLC } \\
\hline & & OH-benzoic acid $(\mu \mathrm{g} / \mathrm{g})$ & $p$-coumaric acid $(\mu \mathrm{g} / \mathrm{g})$ & $o$-coumaric acid $(\mu \mathrm{g} / \mathrm{g})$ \\
\hline Parakou & $100.11 \pm 6.91 \mathrm{c}$ & $802.27 \pm 3.18 \mathrm{a}$ & $772.76 \pm 5.98 \mathrm{bc}$ & $67.86 \pm 1.65 \mathrm{c}$ \\
\hline Ketou & $105.19 \pm 5.08 \mathrm{c}$ & $694.84 \pm 2.86 \mathrm{c}$ & $773.26 \pm 0.06 \mathrm{bc}$ & $94.44 \pm 3.11 \mathrm{~d}$ \\
\hline Toucountouna & $65.43 \pm 1.79 \mathrm{a}$ & $604.95 \pm 10.52 b$ & $594.75 \pm 6.64 \mathrm{ab}$ & $32.73 \pm 2.82 \mathrm{a}$ \\
\hline Boukoumbe & $134.97 \pm 13.69 \mathrm{~d}$ & $1555.39 \pm 18.48 \mathrm{f}$ & $833.62 \pm 7.20 b$ & $134.90 \pm 7.05 \mathrm{e}$ \\
\hline Paouingnan & $71.11 \pm 3.69 \mathrm{ab}$ & $770.05 \pm 13.71 \mathrm{~d}$ & $512.12 \pm 79.99 a$ & $35.07 \pm 2.09 \mathrm{ab}$ \\
\hline Dassa & $96.28 \pm 22.59 \mathrm{bc}$ & $381.01 \pm 2.32 \mathrm{a}$ & $603.01 \pm 181.17 \mathrm{ab}$ & $42.59 \pm 3.27 b$ \\
\hline mean & 95.51 & 801.42 & 681.59 & 67.93 \\
\hline $\mathrm{CV}^{c}$ & 26.67 & 47.48 & 19.97 & 56.80 \\
\hline
\end{tabular}

Table 4. Antioxidant Capacities in the Leaf Sheaths of Dye Sorghum $^{a}$

$\begin{array}{lccc}\text { sample origin } & \text { TEAC }(\mathrm{mmol} / \mathrm{g})^{b} & \begin{array}{c}\text { FRAP } \\ (\mathrm{mmol} / \mathrm{g})\end{array} & \begin{array}{c}\text { DPPH } \\ (\% \text { remaining })\end{array} \\ \text { Parakou } & 5.55 \pm 0.78 \mathrm{~b} & 0.65 \pm 0.01 \mathrm{c} & 84.49 \pm 6.19 \mathrm{a} \\ \text { Ketou } & 4.47 \pm 0.02 \mathrm{ab} & 0.81 \pm 0.00 \mathrm{~d} & 86.85 \pm 0.49 \mathrm{a} \\ \text { Toucountouna } & 3.93 \pm 0.23 \mathrm{a} & 0.49 \pm 0.016 \mathrm{~b} & 78.14 \pm 5.76 \mathrm{a} \\ \text { Boukoumbe } & 5.58 \pm 0.97 \mathrm{~b} & 1.06 \pm 0.06 \mathrm{e} & 80.23 \pm 1.18 \mathrm{a} \\ \text { Paouingnan } & 3.76 \pm 0.66 \mathrm{a} & 0.35 \pm 0.02 \mathrm{a} & 81.46 \pm 9.72 \mathrm{a} \\ \text { Dassa } & 4.53 \pm 0.48 \mathrm{ab} & 0.78 \pm 0.03 \mathrm{~d} & 86.19 \pm 1.42 \mathrm{a} \\ \text { mean } & 4.64 & 0.69 & 82.89 \\ \mathrm{CV}^{c} & 18.74 & 35.31 & 6.21\end{array}$

${ }^{a}$ Results are based on DM. ${ }^{b}$ Mean \pm standard deviation; means with the same letter are not significantly different according to the LSD at the 0.05 level. ${ }^{c}$ Coefficient of variation.

The FRAP assay is based on the reduction of the $\mathrm{Fe}^{3+}-\mathrm{TPTZ}$ complex to the ferrous form at low $\mathrm{pH}$. This reduction is monitored by measuring the absorption change at $595 \mathrm{~nm} .{ }^{23}$ Briefly, $0.2 \mathrm{~mL}$ of sample extract was mixed with $1.3 \mathrm{~mL}$ of the FRAP reagent. Absorption was measured at $595 \mathrm{~nm}$ in a spectrophotometer (U-1100 type, Hitachi, Japan) after $30 \mathrm{~min}$ of incubation at $37^{\circ} \mathrm{C}$. The FRAP reagent was prepared daily and consisted of $0.3 \mathrm{M}$ acetate buffer (pH 3.6), $10 \mathrm{mM} \mathrm{TPTZ}$ in $40 \mathrm{mM}$ $\mathrm{HCl}$, and $20 \mathrm{mM} \mathrm{FeCl}_{3}$ in a ratio of 10:1:1 (v/v/v). FRAP values were obtained by comparing the absorption change in the test mixture to doses obtained from increasing concentrations of $\mathrm{Fe}^{3+}$ and expressed as millimoles of $\mathrm{Fe}^{2+}$ equivalents per gram of leaf sheaths based on DM.

DPPH radical-scavenging activity of sample extracts was determined according to the method reported by Brand-Williams et al. ${ }^{24}$ The reaction mixture consisting of $1.5 \mathrm{~mL}$ of DPPH working solution (4.73 mg of DPPH in $100 \mathrm{~mL}$ of HPLC-grade ethanol) and $300 \mu \mathrm{L}$ sample extract was shaken and incubated for $40 \mathrm{~min}$ in the dark at room temperature. The absorbance was measured at $515 \mathrm{~nm}$ against a blank, using a UV-vis spectrophotometer (Hitachi, Japan). DPPH free radical-scavenging ability was calculated using the following formula:

$$
\begin{aligned}
& \text { scavenging ability }(\%)=\left[\text { absorbance }_{515} \mathrm{~nm}\right. \text { of control } \\
& \left.- \text { absorbance }_{515 \mathrm{~nm} \text { of sample }} / \text { absorbance of control }\right] \times 100
\end{aligned}
$$

Statistical Analysis. Data were reported as the mean \pm standard deviation. The data were analyzed using the statistical program SPSS 11.0 (SPSS, Chicago, IL), and the one-way analysis of variation (ANOVA) model was used applying the least significant difference (LSD) test to evaluate significant difference among means.

\section{RESULTS AND DISCUSSION}

The weights of the leaf sheaths collected in six farming communities of Benin ranged from 0.8 to $2.6 \mathrm{~g}$, with a mean of $1.75 \mathrm{~g}$ (Table 1), and their lengths ranged from 22.1 to $27 \mathrm{~cm}$, with an average of $25 \mathrm{~cm}$. The mean values of the basal, middle, and terminal width are $1.9,1.3$, and $1 \mathrm{~cm}$, respectively.

Anthocyanidin Content. The anthocyanin contents, expressed as cyanidin 3-glucoside, estimated by spectrophotometry were on average $18.5 \%$ lower than the HPLC data (Table 2). The reason for this underestimation lies in the different absorption maxima of anthocyanidins and deoxyanthocyanidins, which are above $500 \mathrm{~nm}$ at $\mathrm{pH} 1$ for anthocyanidins and their glycosides and around $470 \mathrm{~nm}$ for 3-deoxyanthocyanidins. ${ }^{25}$ However, both methods generally correlated well ( $r=0.961$ and 0.852$)$ for ACY and apigeninidin or luteolinidin contents at $p \leq 0.001$, respectively. The ACY of leaf sheaths ranged from 13.7 to $35.5 \mathrm{mg}$ of C-3-glc/g, with an average value of $27.1 \mathrm{mg} / \mathrm{g}$. Analytical separation of anthocyanidins on the HPLC system allowed us to detect apigeninidin, luteolinidin, and malvidin as the major anthocyanidin compounds of the leaf sheaths of dye sorghum (Figure 1). The level of apigeninidin ranged from 14.7 to $45.8 \mathrm{mg} / \mathrm{g}$, with an average value of $31.3 \mathrm{mg} / \mathrm{g}$. The luteolinidin amount ranged from 0.43 to $2.35 \mathrm{mg} / \mathrm{g}$, while the malvidin content averaged $0.70 \mathrm{mg} / \mathrm{g}$. Clearly, we observed uncommonly high levels of 3-deoxyanthocyanindins in the leaf sheaths of dye sorghum. Particularly, the level of apigeninidin was 30 times higher than that in cereal bran, and the ACY is 90 times higher than levels usually reported in fruits and vegetables (Table 5).

With respect to origin, leaf sheaths from Ketou showed the highest content of ACY, luteolinidin, and malvidin. Apigeninidin was highest in the sample originating from Boukoumbe, followed by the samples from Dassa and Ketou. Apparently, the concentration of 3-anthocyanindins is linked to the genetic makeup of the crop and/or the environmental conditions. This result is corroborated by Ortega-Regules et al., ${ }^{26}$ who indicate that the level and stability of these phenolic substances may vary according to the genetic and environmental conditions. Likewise, a study by Dykes et al. ${ }^{27}$ revealed that the phenolic concentration in the sorghum grain is genetically determined. Thus, there might be a possibility to increase the amount of these phytochemicals through breeding and crop management. Further studies are needed to determine the contribution of the individual factors to the amount of anthocyanidins in the leaf sheaths of dye sorghum.

Phenolic Acid Content. TPC of the different extracts was expressed as GAE per gram of DM. The highest TPC was found 
Table 5. Comparison of Leaf Sheaths of Dye Sorghum to Other Dye Sources for Their Anthocyanin Contents and Antioxidant Properties

\begin{tabular}{|c|c|c|c|c|}
\hline commodity & $\mathrm{TPC}(\mathrm{mg} / \mathrm{g})$ & $\mathrm{ACY}(\mathrm{mg} / \mathrm{g})$ & total antioxidant activity & reference \\
\hline leaf sheaths of dye sorghum & $65.4-135.0^{a}$ & $13.7-35.5^{b}$ & $\begin{array}{l}\text { FRAP: } 350.0-1060.1 \mu \mathrm{mol} / \mathrm{g} \text { of DM } \\
\text { DPPH: } 78.1-86.8 \% \mathrm{rem}^{c} \\
\text { TEAC: } 3760.6-5580.9 \mu \mathrm{mol} / \mathrm{g} \text { of DM }\end{array}$ & this work \\
\hline black sorghum bran & & $4.7-11.0^{d}$ & $\begin{array}{l}\text { TEAC: } 261.0-400.0 \mu \mathrm{mol} / \mathrm{g} \text { of DM } \\
\text { FRAP: } 36.5-75.8 \mu \mathrm{mol} / \mathrm{g} \text { of DM }\end{array}$ & Awika et al. (2004) \\
\hline black rice & $3.4-6.7^{e}$ & $1.1-2.6^{b}$ & $\begin{array}{l}\text { DPPH: } 16.0-30.3 \% \mathrm{rem}^{c} \\
\text { TEAC: } 49.8-120.3 \mu \mathrm{mol} / \mathrm{g} \text { of DM } \\
\text { FRAP: } 8.5-80.8 \mu \mathrm{mol} / \mathrm{g} \text { of DM }\end{array}$ & Sompong et al. (2011) \\
\hline red rice & $0.8-6.9^{e}$ & $0.0-0.01^{b}$ & $\begin{array}{l}\text { DPPH: } 13.0-62.8 \% \mathrm{rem}^{c} \\
\text { TEAC: } 20.8-122.9 \mu \mathrm{mol} / \mathrm{g} \text { of DM }\end{array}$ & Sompong et al. (2011) \\
\hline blueberry & & & FRAP: $116 \mu \mathrm{mol} / \mathrm{g}$ of $\mathrm{FW}$ & Dragović-Uzelac et al. (2009) \\
\hline commercial & $2.2^{f}$ & $1.7^{g}$ & DPPH: $16 \mu \mathrm{mol}$ of $\mathrm{TE}^{h} / \mathrm{g}$ of FW & Garzón et al. (2010) \\
\hline wild type & $7.6^{f}$ & $3.3^{g}$ & TEAC: $45.5 \mu \mathrm{mol} / \mathrm{g}$ of $\mathrm{FW}$ & Denev et al. (2010) \\
\hline sour cherry & $2.6^{f}$ & $1.9^{g}$ & DPPH: $17 \mu \mathrm{mol}$ of TE/g of $\mathrm{FW}^{h}$ & Dragović-Uzelac et al. (2009) \\
\hline \multicolumn{5}{|l|}{ blackberry } \\
\hline wild type & & $6.6-9.2^{b}$ & & Cuevas-Rodríguez et al. (2010) \\
\hline commercial & & $3.4^{b}$ & & Cuevas-Rodríguez et al. (2010) \\
\hline cultivar & & $0.16^{b}$ & & Denev et al. (2010) \\
\hline black currant & & $0.28^{b}$ & & Denev et al. (2010) \\
\hline red raspberry & $1.49-3.48^{f}$ & $0.20^{i}$ & $\begin{array}{l}\text { FRAP: } 19.8 \mu \mathrm{mol} / \mathrm{g} \text { of } \mathrm{FW} \\
\text { TEAC: } 21.5 \mu \mathrm{mol} / \mathrm{g} \text { of FW }\end{array}$ & Çekiç and Özgen (2008) \\
\hline strawberry & $1.7-3.1^{f}$ & $0.10-0.30^{j}$ & TEAC: $14.18 \mu \mathrm{mol} / \mathrm{g}$ of FW & Tulipani et al. (2008) \\
\hline elderberry & & $\begin{array}{l}2.0-10.0 \mathrm{wb} \\
0.63^{b}\end{array}$ & & Denev et al. (2010) \\
\hline red cabbage & $0.13-0.17^{f}$ & $\begin{array}{l}0.60-0.85^{g} \\
0.76^{g}\end{array}$ & TEAC: $10-12.5 \mu \mathrm{mol} / \mathrm{g}$ of $\mathrm{FW}$ & $\begin{array}{l}\text { Podsędek et al. (2008) } \\
\text { Scalzo et al. (2008) }\end{array}$ \\
\hline red onion & $15.56^{a}$ & $0.45^{b}$ & $\begin{array}{l}\text { DPPH: } 41.32 \mu \mathrm{M} \mathrm{TE} / \mathrm{g} \text { of DM } \\
\text { TEAC: } 58.94 \mu \mathrm{M} \text { TE/g of DM }\end{array}$ & Gorinstein et al. (2009) \\
\hline
\end{tabular}

${ }^{a} \mathrm{mg}$ of GAE/g of DM. ${ }^{b} \mathrm{mg}$ of C-3-glc/g of DM. ${ }^{c} \%$ remaining DPPH at $t=40 \mathrm{~min} .{ }^{d} \mathrm{mg}$ of luteolinidin equivalents/g of DM. ${ }^{e} \mathrm{mg}$ of ferulic acid equivalent/g of DM. ${ }^{f} \mathrm{mg}$ of GAE/g of FW. ${ }^{g} \mathrm{mg}$ of C-3-glc/g of FW. ${ }^{h}$ Trolox equivalent (TE). ${ }^{i} \mathrm{mg}$ of C-3-soph/g of FW. ${ }^{j}$ ACY based on HPLC data, $\mathrm{mg} / \mathrm{g}$ of FW.

in the sample from Boukoumbe, followed by Ketou and Parakou (Table 3), with 135, 105, and $100 \mathrm{mg}$ of GAE/g of DM, respectively. Only hydroxybenzoic, $o$-coumaric, and $p$-coumaric acids were detected. However, leaf sheaths from Boukoumbe contained 4 times more 4-OH-benzoic acid than samples from Dassa, with 1555 versus $381 \mu \mathrm{g} / \mathrm{g}$ of DM. $p$-Coumaric acid was found as the second dominant phenolic acid, ranging from 512 to $834 \mu \mathrm{g} / \mathrm{g}$, whereas $o$-coumaric acid was on average 1 magnitude lower. Co-pigmentation of deoxyanthocyanidins can improve the anthocyanidin stability and color intensity in moderately acidic environments as investigated by Awika. ${ }^{28}$

Antioxidant Capacity. The total antioxidant capacity describes the cumulative capacity of food components to scavenge free radicals, and high intakes of dietary TAC have been related to several health benefits in both cross-sectional and randomized intervention studies. In this context, methanolic extracts of leave sheaths were assessed for their antioxidant properties.

All samples showed very high antioxidant capacity (Table 4). The highest ABTS radical-scavenging ability was found in the leaf sheaths from Boukoumbe and Parakou, respectively, followed by leaf sheaths from Ketou and Dassa. FRAP values were, in general, lower than the respective TEAC values but followed the same order. Despite the variation in TEAC and FRAP values, no significant difference between the samples was found when
DPPH was used. As described by Arnao, ${ }^{29}$ color interference of the sorghum extracts might have led to great variations within the samples and masked the underlying differences. On the other hand, phenolic acids react differently with different radicals. Table 5 summarizes TPC, ACY, and antioxidant capacity of other anthocyanin-rich plant sources. The dye sorghum largely surpasses the other plant commodities for its TPC and anthocyanin content. It also ranks first for antioxidant capacity among other anthocyaninrich plant species. Clearly, the dye sorghum showed a comparative advantage as a deoxyanthocyanidin and antioxidant source compared to cereal bran and fruits and vegetables.

Relationship between Anthocyanidin and Phenolic Acid Content and Antioxidant Capacity of Dye Sorghum. TPC correlated strongly with the ACY and the antioxidant capacity, particularly when measured with the FRAP assay (Table 6). ACY significantly correlated with levels of apigeninidin $(r=0.96 ; p \leq 0.01)$ and luteolinidin $(r=0.85 ; p \leq 0.01)$, while no significant relationship could be found between apigeninidin and luteolinidin, as previously reported in grain sorghum. ${ }^{27}$ Correlation experiments to predict the antioxidant capacity have been performed by many others, with different observations; a high correlation was found between TEAC and TPC in strawberries $(r=0.95),{ }^{30}$ red cabbage $(r=0.98),{ }^{31}$ red raspberries $(r=0.74),{ }^{32}$ milling fractions of pigmented wheat and barley $(r=0.96),{ }^{20}$ and red and black rice varieties $(r=0.93){ }^{33}$ 
Table 6. Pearson Correlation Matrix between ACY and TPC and the Antioxidant Capacity

\begin{tabular}{|c|c|c|c|c|}
\hline & $\mathrm{ACY}$ & TPC & TEAC & FRAP \\
\hline TPC & $0.796^{a}$ & & & \\
\hline TEAC & $-0.087 \mathrm{~ns}^{b}$ & $0.719^{a}$ & & \\
\hline FRAP & $0.847^{a}$ & $0.890^{a}$ & $0.662^{c}$ & \\
\hline $\mathrm{DPPH}$ & $0.454 \mathrm{~ns}^{b}$ & $0.156 \mathrm{~ns}^{b}$ & $-0.087 \mathrm{~ns}^{b}$ & $0.165 \mathrm{~ns}^{b}$ \\
\hline
\end{tabular}

TEAC and anthocyanins by HPLC $(r=0.90)$ correlated in a study of red cabbage, ${ }^{31}$ and TEAC and total monomeric anthocyanidins $(r=$ 0.74 ) correlated in a study of red raspberries, ${ }^{32}$ whereas Tulipani et al. ${ }^{30}$ found no correlation between ACY and TEAC $(r=-0.07)$ in strawberries. Denev et al. ${ }^{34}$ found that the antioxidant capacity correlated in general better with the polyphenol content than the anthocyanin content and was highest for TPC and FRAP $(r=0.95)$ when different berries were compared.

Pair-wise correlations between the different assays to measure the antioxidative capacity were found between TEAC and FRAP at $r=0.81$ in red raspberries, ${ }^{32}$ at $r=0.95$ and $p \leq 0.001$ in strawberries, ${ }^{30}$ at $r=0.90$ and $p<0.0001$ in milling fractions of pigmented wheat and barley, ${ }^{20}$ and at $r=0.93$ in red and black rice varieties, ${ }^{33}$ where in addition to these findings, high negative correlation coefficients were obtained between DPPH and FRAP $(r=-0.81)$ and between TEAC and DPPH $(r=-0.66)$.

In conclusion, the analyzed dye sorghum contains a very high level of anthocyanidins, which mainly consists of apigeninidin and luteolinidin, two 3-deoxyanthocyanidins with high stability under processing conditions. These two pigments are not common in plant species. The crude extract from the leaf sheath also showed very high antioxidant capacity. The exploitation of the dye sorghum as a multipurpose crop to produce biocolorant and food grain could be envisaged. Research initiatives are being taken to generate more knowledge on this crop and to valorize it for the benefit of rural farmers in Benin.

\section{AUTHOR INFORMATION}

\section{Corresponding Author}

*Telephone: +229-97870734. E-mail: polykap@yahoo.fr.

\section{Funding Sources}

The International Foundation for Science (IFS), Stockholm, Sweden, is acknowledged for financial support to A. P. Polycarpe Kayodé (Grant IFS E/3736-2). Support provided by the Department of Food Science and Technology, University of Natural Resources and Life Sciences, Vienna, Austria, is gratefully acknowledged.

\section{ACKNOWLEDGMENT}

Thanks are due to Michael Prückler for laboratory assistance.

\section{ABBREVATIONS USED}

ABTS, 2,2'-azinobis(3-ethylbenzothiazoline-6-sulfonic acid); C-3-glc, cyanidin-3-glucoside; ACY, total anthocyanidin content; $\mathrm{DM}$, dry matter; DPPH, 2,2'-diphenyl-1-picrylhydrazyl; FW, fresh weight; FRAP, ferric reducing antioxidant power; GAE, gallic acid equivalent; TAC, total antioxidant capacity; TEAC, Trolox antioxidant capacity assay; TPC, total phenolic content; TPTZ, 2,4,6-tripyridyl-s-triazine

\section{REFERENCES}

(1) Magda, T. R. Going back to natural red colors (red sorghum, cochineal, and Monascus). Drink Technol. Mark. 2003, 7, 1433-1594.

(2) Bao, J.; Cai, Y. M.; Sun, M.; Wang, G.; Corke, H. Anthocyanins, flavonols, and free radical scavenging activity of Chinese bayberry (Myrica rubra) extracts and their color properties and stability. J. Agric. Food Chem. 2005, 53, 2327-2332.

(3) Giusti, M.; Wrolstad, R.; Gloria, M. Anthocyanins from banana bracts as potential food colorants. Food Chem. 2001, 73, 327-332.

(4) Dicko, M. H.; Gruppen, H.; Traore, A. S.; Voragen, A. G. J.; Van Berkel, W. J. H. Sorghum grain as human food in Africa: Relevance of content of starch and amylase activities. Afr. J. Biotechnol. 2006, 5, 384-395.

(5) Boon, E. J. M. C.; Engels, F. M.; Struik, P. C.; Cone, J. W. Stem characteristics of two forage maize (Zea mays L.) cultivars varying in whole plant digestibility. II. Relation between in vitro rumen fermentation characteristics and anatomical and chemical features within a single internode. NJAS-Wageningen J. Life Sci. 2005, 53, 87-111.

(6) Lo, S. C. C.; Nicholson, R. L. Reduction of light-induced anthocyanin accumulation in inoculated sorghum mesocotyls: Implication for a compensatory role in the defense response. Plant Physiol. 1998, 116, 979-989.

(7) Lo, S. C. C.; de Verdier, K.; Nicholson, R. L. Accumulation of 3-deoxyanthocyanidin phytoalexins and resistance to Colletotrichum sublineolum in sorghum. Physiol. Mol. Plant Pathol. 1999, 55, 263-273.

(8) Nip, W. K.; Burns, E. E. Pigment characterization in grain sorghum. I. red varieties. Cereal Chem. 1969, 46, 490-495.

(9) Nip, W. K.; Burns, E. E. Pigment characterization in grain sorghum. II. White varieties. Cereal Chem. 1971, 48, 74-80.

(10) Kouda-Bonafos, M.; Czyzewska, E; Nacro, M.; Oehlschlager, A. C. Isolation of apigeninidin from leaf sheaths of sorghum caudatum. J. Chem. Ecol. 1994, 20, 2123-2125.

(11) Gous, F. Tannins and phenols in black sorghum. Ph.D. Dissertation, Texas A\&M University, College Station, TX, 1989.

(12) Awika, J. M.; Rooney, L. W.; Waniska, R. D. Properties of 3-deoxyanthocyanins from sorghum. J. Agric. Food Chem. 2004, 52, 4388-4394.

(13) Awika, J. M.; Rooney, L. W.; Waniska, R. D. Anthocyanins from black sorghum and their antioxidant properties. Food Chem. 2004, 90, 293-301.

(14) Shih, C. H.; Siu, S. O.; Ng, R.; Wong, E.; Chiu, L. C., M.; Chu, I. K.; Lo, C. L. Quantitative analysis of anticancer 3-deoxyanthocyanidins in infected sorghum seedlings. J. Agric. Food Chem. 2007, 55, 254-259.

(15) Yang, L.; Browning, J. D.; Awika, J. M. Sorghum 3-deoxyanthocyanins possess strong phase II enzyme inducer activity and cancer cell growth inhibition properties. J. Agric. Food Chem. 2009, 57, 1797-1804.

(16) Saïdou, A.; Kuyper, T. W.; Kossou, D. K.; Tossou, R.; Richard, P. The sustainable soil fertility management in Benin: learning from farmers. NJAS-Wageningen J. Life Sci. 2004, 52, 349-368.

(17) Faure, P. Notice explicative No. 66, carte pédologique de reconnaissance de la République Populaire du Bénin à 1/200.000, Feuille de Natitingou (6)-Porga (8); Travaux et documents de l'ORSTOM, Paris, France, 1977; p 68.

(18) Abdel-Aal, E.-S. M.; Hucl, P. A rapid method for quantifying total anthocyanins in blue aleurone and purple pericarp wheat. Cereal Chem. 1999, 76, 350-354.

(19) Singleton, V. L.; Rossi, J. A. Colorimetry of total phenolics with phosphomolybdic-phosphotungstic acid reagents. Am. J. Enol. Vitic. $1965,16,144-158$.

(20) Siebenhandl, S.; Grausgruber, H.; Pellegrini, N.; Del Rio, D.; Fogliano, V.; Pernice, R.; Berghofer, E. Phytochemical profile of main antioxidants in different fractions of purple and blue wheat, and black barley. J. Agric. Food Chem. 2007, 55, 8541-8547.

(21) Pellegrini, N.; Del Rio, D.; Colombi, B.; Bianchi, M.; Brighenti, F. Application of the 2,2'-azobis(3-ethylenebenzothiazoline-6-sulfonic acid) radical cation assay to a flow injection system for the evaluation of antioxidant activity of some pure compounds and beverages. J. Agric. Food Chem. 2003, 51, 260-264. 
(22) Moore, J.; Hao, Z.; Zhou, K.; Luther, M.; Costa, J.; Yu, L. L. Carotenoid, tocopherol, phenolic acid, and antioxidant properties of Maryland-grown soft wheat. J. Agric. Food Chem. 2005, 53, 6649-6657.

(23) Benzie, I. F. F.; Strain, J. J. Ferric reducing/antioxidant power assay: Direct measure of total antioxidant activity of biological fluids and modified version for simultaneous measurement of total antioxidant power and ascorbic acid concentration. Methods Enzymol. 1999, 299, $15-27$.

(24) Brand-Williams, W.; Cuvelier, M. E.; Berset, C. Use of a free radical method to evaluate antioxidant activity. Lebensm.-Wiss. Technol. $1995,28,25-30$.

(25) Fossen, T.; Cabrita, L.; Andersen, $\varnothing$. Colour and stability of pure anthocyanins influenced by $\mathrm{pH}$ including the alkaline region. Food Chem. 1998, 63, 435-440.

(26) Ortega-Regules, A.; Romero-Cascales, I.; López-Roca, J. M.; Ros-Garcia, J. M.; Gómez-Plaza, E. Anthocyanin fingerprint of grapes: Environmental and genetic variation. J. Sci. Food Agric. 2006, 86, 1460 1467.

(27) Dykes, L.; Rooney, L. W.; Waniska, R. D.; Rooney, W., L. Phenolic compounds and antioxidant activity of Sorghum grain of varying genotypes. J. Agric. Food Chem. 2005, 53, 6813-6818.

(28) Awika, J. M. Behaviour of 3-deoxyanthocyanidins in the presence of phenolic copigments. Food Res. Int. 2008, 41, 532-538.

(29) Arnao, M. B. Some methodological problems in determination of antioxidant activity using chromogen radicals: A practical case. Trends Food Sci. Technol. 2000, 11, 419-421.

(30) Tulipani, S.; Mezzetti, B.; Capocasa, F.; Bompadre, S.; Beekwilder, J.; Rice de Vos, C. H.; Capanoglu, E.; Bovy, A.; Battino, M. Antioxidants, phenolic compounds, and nutritional quality of different strawberry genotypes. J. Agric. Food Chem. 2008, 56, 696-704.

(31) Podsędek, A.; Sosnowska, D.; Redzynia, M.; Koziolkiewicz, M. Effect of domestic cooking on the red cabbage hydrophilic antioxidants. Int. J. Food Sci. Technol. 2008, 43, 1770-1777.

(32) Çekiç, Ç.; Özgen, M. Comparison of antioxidant capacity and phytochemical properties of wild and cultivated red raspberries (Rubus idaeus L.). J. Food Compos. Anal. 2010, 23, 540-544.

(33) Sompong, R.; Siebenhandl-Ehn, S; Linsberger-Martin, G.; Berghofer, E. Physicochemical and antioxidative properties of red and black rice varieties from Thailand, China and Sri Lanka. Food Chem. 2011, 124, 132-140.

(34) Denev, P.; Ciz, M.; Ambrozova, G.; Lojek, A.; Yanakieva, I.; Kratchanova, M. Solid-phase extraction of berries' anthocyanins and evaluation of their antioxidative properties. Food Chem. 2010, 123, 1055-1061. 